\title{
Cognitive dissonance: Physiological arousal in the performance expectancy paradigm
}

\author{
MICHAEL P. ETGEN and ELLEN F. ROSEN \\ College of William and Mary, Williamsburg, Virginia
}

\begin{abstract}
The physiological correlates of dissonance were investigated using a replication of Aronson and Carlsmith's (1962) performance expectancy paradigm. Dissonance was predicted to be associated with an increased heart rate and skin conductance response (SCR). This prediction was partially supported; dissonance was significantly related to heart rate changes, but not to SCR. The results are discussed in terms of their implications for the performance expectancy paradigm and its relationship to dissonance and arousal.
\end{abstract}

Research on Festinger's (1957) theory of cognitive dissonance has demonstrated that the need for cognitive consistency is so strong that subjects will "perform to fail" if their expectancy on a task is lower than their previous performance (Aronson \& Carlsmith, 1962). Varying the strength of subjects' expectancies yielded similar results, except when they were given feedback on every single trial. With this procedure, only achievement needs were seen. Subjects who had performed poorly either attempted to remedy their poor performance with a better one, or randomly answered questions because of a feeling of lack of control or self-irrelevancy (Brock, Edelman, Edwards, \& Schuck, 1965). Mettee (1971) extended Aronson and Carlsmith's findings by adding a "future interview" condition, in which subjects expected that a future interview with a clinical psychologist would find them to be lacking in task ability. Maracek and Mettee (1972) added a pretest self-esteem measure and a skill-chance distinction to the design. With these added conditions, subjects who were certain of their low self-esteem rejected success only if their performance was apparently under their control (self-relevant).

Other researchers have found no "perform to fail" phenomena in their studies (Cottrell, 1965; Lowin \& Epstein, 1965; Ward \& Sandvold, 1963). In these studies, the subjects' achievement needs seemed to win out over their need to reduce inconsistency. It is possible that they were given a low expectancy, but were uncertain of their designation as poor performers (Maracek \& Mettee, 1972); achievement needs would then be more important than consistency. Another possibility is that the subjects perceived their performance as due to self-irrelevancy (e.g., Brock et al., 1965).

Physiological arousal is a concomitant of cognitive dissonance. Croyle and Cooper (1983) found that high-choice condition subjects displayed significantly more nonspecific skin conductance responses (SCRs) than did subjects in

Requests for reprints should be sent to E. F. Rosen, Department of Psychology, College of William and Mary, P.O. Box 8795, Williamsburg, VA 23187-8795. other conditions, and incorrectly misattributed their arousal to the recording device, thereby producing selfirrelevancy and no need to reduce the tension of dissonance. Cooper and Fazio (1984) and Kiesler and $\mathrm{Pal}-$ lak (1976) found that dissonance involves physiological arousal that is experienced as a negative state, but only if the arousal is attributed to subjects' own attitudediscrepant behavior. Thus, there is clearly a relationship between physiological arousal and cognitive dissonance.

The present study attempted to examine more closely the relationship between physiological arousal and dissonance by using the performance expectancy paradigm of Aronson and Carlsmith (1962). In this paradigm, an individual subject's expectancy is manipulated by controlled feedback during four trials. On the fifth trial, the subject is given feedback that is either consistent or inconsistent with their expectancy. Heart rate and SCR were measured during the trials. Feedback on the fifth trial, consistent with the subject's high or low expectancy, should be consonant and unarousing, whereas inconsistent feedback should be dissonant and produce arousal. Dissonance should produce significantly greater average SCR and heart rate. The direction of the disconfirmation of the subject's expectancy (whether high to low or low to high) was expected to produce no difference in arousal measures; both should produce similar discomfort.

\section{METHOD}

\section{Subjects}

Forty-two undergraduates, enrolled in an introductory psychology course at the College of William and Mary, served as subjects. Al received credit for research participation.

\begin{abstract}
Materials
The physiological recording devices used in this experiment were a Grass Polygraph Model 7 (Grass Instruments, Quincy, MA) and an SCR64 (Autogenic Systems, Stoelting Co., Chicago, IL) skin conductance response machine. The polygraph tachograph unit (7P4) measured heart rate in beats per minute, and the SCR- 64 measured the average percent of change of skin resistance during the baseline and experimental periods.

There were 100 stimulus cards. Each card displayed three pictures of young men and women, randomly selected from either William and Mary or James Madison University 1987 and 1988 yearbooks.
\end{abstract}




\section{Design and Procedure}

The cards were divided into five sets of 20 cards each. Each picture on a card had an A, B, or C beside it. The subjects were told that one person on each of the cards was schizophrenic, and that they were to test their ability in the new area of "psychological sensitivity" by trying to identify that person. The subjects went through the cards individually, and verbally announced their choice. The experimenter wrote down their answers while the subjects flipped the card over and went on to the next one. They were allowed $10 \mathrm{sec}$ per card.

The subjects were told that this test was an excellent measure of how sensitive an individual is to other people, and that those who did poorly usually had a very superficial understanding of other people, and those who did well usually had a great deal of insight into other people. The subjects were also told that some participants could get as many as $85 \%$ correct, but others might get only about $20 \%$ correct. They were further told how difficult it was to judge one's own performance on the test, and that usually those who thought they did well actually did poorly, and vice versa. The design was that of Aronson and Carlsmith (1962), without the self-rating scale pretest.

There was about a 2 -min rest period between each trial (set of 20 cards), which allowed the experimenter to "grade" the performance of the subjects and tell them how they were doing. The experimenter graded each set by randomly marking answers as either incorrect or correct. Feedback after each set was given so that a consistent performance expectancy would be built over the course of the first four trials. The measure of the baseline heart rate and SCR were taken during the third trial and the following rest period. It was assumed that by then the subjects would be comfortable with their physical surroundings as well as with their high or low performance expectancy.

After the fifth trial was completed, the experimenter pretended to be chagrined at the fact that he had forgotten to take statistics on the physiological measures for the last set. The subjects were told that the physiological data were quite important to the experiment and that their data would be useless without it. They were asked to repeat the last set over again, and all the subjects agreed. The experimenter asked the subjects to score their own last set with the bogus "key" he had written during their last trial. After they graded their own fifth set, the experimenter recorded it and let them relax again for about $30 \mathrm{sec}$ before retaking the fifth set. While the subjects graded their last set, and during the 30-sec rest period, the experimental heart rate and SCR were recorded by the investigator.

The experimenter told each subject to pretend that the fifth set was a completely new set of pictures. After the subjects completed the last set, the experimenter revealed the true purpose of the study and the necessity for the deception. All the subjects were surprised by the true purpose, but expressed no indignation at having been deceived. Most of them actually expressed a good deal of interest in the design and questioned the investigator at length.

\section{Experimental Conditions and Dependent Variables}

The subjects were randomly assigned to one of four conditions. Each subject was given either a high or low performance expectancy on the first four trials. The high scores were 16 or 17 correct, and the low scores were 4 or 5 correct. Each subject was given a fifth trial score that was either consistent or inconsistent with their expectancy. The high scores given on the fifth trial were all 17 , and the low scores were 4.
Seven subjects were given a score consistent with their high expectancy (High-High); 9 subjects were given one consistent with their low expectancy (Low-Low); 13 subjects were given a score inconsistent with their high expectancy (High-Low); and 13 subjects were given a score inconsistent with their low expectancy (Low-High).

The dependent variables measured were the number of answers changed on the fifth set retake, and the physiological measurements during the 30 -sec rest period (baseline) and grading (experimental).

\section{RESULTS}

Table 1 shows the means for the number of answers changed, heart rate, and SCR for each of the four conditions.

An analysis of variance (ANOVA) of the number of answers changed revealed that the interaction between the expectancy and the fifth trial performance was highly significant $[F(1,38)=64.704, p<.001]$. Tukey's $H S D$ tests revealed significant differences between the experimental (High-Low, Low-High) and the control groups (Low-Low, High-High), but not within them.

The differences between each subject's resting and experimental heart rate and SCR were computed by subtracting the resting from the experimental measures. An ANOVA on these data (expectancy $\times$ change in fifth set performance level) produced a significant factor for expectancy $[F(1,38)=7.99, p<.01]$, for fifth set performance change $[F(1,38)=11.01, p<.01]$, and for the interaction $[F(1,38)=7.423, p<.01]$. The parallel ANOVA on the SCR differences produced no significant differences.

\section{DISCUSSION}

The data support the prediction that the subjects would make significantly more answer changes if their performance on the fifth trial was made to be inconsistent with their expectancy, which matches the findings of Aronson and Carlsmith (1962). The subjects in each condition were given a very strong expectancy about their performance that was resistant to change. Thus, they attempted to confirm their expectancy on the retake by changing a significantly larger number of answers than did the subjects with no inconsistency.

The heart rate data did not confirm our predictions. The Low-Low group showed the greatest increase in heart rate (almost six times that of any group). The Low-High group had the next highest increase, suggesting that a low expectancy produced an increase in heart rate during the scoring process.

The lack of significance for the SCR data may suggest that there is a difference between SCR and heart rate measures accompanying dissonance. Croyle and Cooper (1983) found a nonsignificant relationship between the two measures, but found results supportive of dissonance

Table 1

Means and Standard Deviations for Number of Answers Changed, Heart Rate, and SCR* Differences Scores for Each of the Four Conditions

Condition (Expectancy/Assigned

Fifth Set Performance)

\begin{tabular}{|c|c|c|c|c|c|c|c|c|}
\hline & \multicolumn{2}{|c|}{ Low-Low } & \multicolumn{2}{|c|}{ Low-High } & \multicolumn{2}{|c|}{ High-Low } & \multicolumn{2}{|c|}{ High-High } \\
\hline & $M$ & $S D$ & $M$ & $S D$ & $M$ & $S D$ & $M$ & $S D$ \\
\hline To. Answers Changed & 4.67 & 1.5 & 8.77 & 1.8 & 10.0 & 2.5 & 3.86 & 1.57 \\
\hline Heart Rate & 6.21 & 5.8 & .45 & 1.5 & .92 & 1.4 & .36 & 1.93 \\
\hline SCR & -.001 & .04 & .13 & .40 & .10 & .34 & .05 & .16 \\
\hline
\end{tabular}

*Skin conductance response. 
as an arousal process. They used the frequency of SCRs as the measure, as opposed to the average percentage of change from the baseline. In the present study, heart rate seemed less likely than SCR to be influenced by extraneous factors, such as the temperature of the room during testing. On the other hand, the SCR data, though nonsignificant, did follow the predicted pattern that heart rate did not.

Dissonance was elicited in the inconsistency groups, and the number of answers changed support that idea. The need for cognitive consistency is quite powerful. When confronted with inconsistency, subjects will, if necessary to regain consistency, "perform to fail." Perhaps the physiological measurements need to be made just at the moment the dissonance is about to be resolved; the failure to find significant physiological changes in the predicted pattern may have come about because of the timing of the measures. The appropriate time to measure arousal may be during the repeat of the fifth trial, as subjects are changing their answers. The fact that SCR produced the predicted pattern suggests that it may be a better predictor of dissonance reduction than heart rate, which seems to mainly reflect anticipation of confirmation of poor performance.

\section{REFERENCES}

Aronson, E., \& Carlsmith, J. M. (1962). Performance expectancy as a determinant of actual performance. Journal of Abnormal \& Social Psychology, 65, 178-182.

Brock, T., Edelman, S., Edwards, D., \& Schuck, J. (1965). Seven studies of performance expectancy as a determinant of actual performance. Journal of Experimental Social Psychology, 1, 295-310.
CoOper, J., \& FAzio, R. H. (1984). A new look at dissonance theory. In L. Berkowitz (Ed.), Advances in experimental social psychology (Vol. 17, pp. 229-266). New York: Academic Press.

Cottrell, N. B. (1965). Performance expectancy as a determinant of actual performance: A replication with a new design. Journal of Personality \& Social Psychology, 2, 685-691.

Croyle, R. I., \& CoOper, J. (1983). Dissonance arousal: Physiological evidence. Journal of Personality \& Social Psychology, 45, 782-791.

FESTINGER, L. (1957). A theory of cognitive dissonance. Stanford, CA Stanford University Press.

Kiesler, C. A., \& Pallak, M. S. (1976). Arousal properties of dissonance manipulations. Psychological Bulletin, 83, 1014-1025.

Lowin, A., \& Epstein, G. F. (1965). Does expectancy determine performance? Journal of Experimental Social Psychology, 1, 248-255.

MaraceK, J., \& MetTeE, D. R. (1972). Avoidance of continued success as a function of self-esteem, level of esteem certainty, and responsibility for success. Journal of Personality \& Social Psychology, 22, 98-107.

MetTEE, D. R. (1971). Rejection of unexpected success as a function of the negative consequences of accepting success. Journal of Personality \& Social Psychology, 17, 332-341.

WARD, W. D., \& SANDVold, K. D. (1963). Performance expectancy as a determinant of actual performance: A partial replication. Journal of Abnormal \& Social Psychology, 67, 293-295.

(Manuscript received November 16, 1992.) 